\title{
Determination of uranium concentration and burn-up of irradiated reactor fuel in contaminated areas in Belarus using uranium isotopic ratios in soil samples
}

\author{
By V. P. Mironov ${ }^{1}$, J. L. Matusevich¹, V. P. Kudrjashov' ${ }^{1}$, P. I. Ananich ${ }^{1}$, V. V. Zhuravkov ${ }^{1}$, S. F. Boulyga ${ }^{2}$,* and J. S. Becker ${ }^{3}$ \\ ${ }^{1}$ Institute of Radiobiology, 220141 Minsk, Belarus \\ 2 Institute of Inorganic Chemistry and Analytical Chemistry, Johannes Gutenberg-University Mainz, Duesbergweg 10-14, \\ 55099 Mainz, Germany \\ ${ }^{3}$ Central Division of Analytical Chemistry, Research Centre Juelich, 52425 Juelich, Germany
}

(Received May 25, 2005; accepted in revised form July 1, 2005)

\section{Reactor fuel / Burn-up / Environmental contamination / Uranium isotopic analysis / \\ Inductively coupled plasma mass spectrometry}

Summary. An analytical method is described for the estimation of uranium concentrations, of ${ }^{235} \mathrm{U} /{ }^{238} \mathrm{U}$ and ${ }^{236} \mathrm{U} /{ }^{238} \mathrm{U}$ isotope ratios and burn-up of irradiated reactor uranium in contaminated soil samples by inductively coupled plasma mass spectrometry. Experimental results obtained at 12 sampling sites situated on northern and western radioactive fallout tails 4 to $53 \mathrm{~km}$ distant from Chernobyl nuclear power plant (NPP) are presented. Concentrations of irradiated uranium in the upper $0-10 \mathrm{~cm}$ soil layers at the investigated sampling sites varied from $2.1 \times 10^{-9} \mathrm{~g} / \mathrm{g}$ to $2.0 \times 10^{-6} \mathrm{~g} / \mathrm{g}$ depending mainly on the distance from Chernobyl NPP. A slight variation of the degree of burn-up of spent reactor uranium was revealed by analyzing ${ }^{235} \mathrm{U} /{ }^{238} \mathrm{U}$ and ${ }^{236} \mathrm{U} /{ }^{238} \mathrm{U}$ isotope ratios and the average value amounted to $9.4 \pm 0.3 \mathrm{MWd} /(\mathrm{kg} \mathrm{U})$.

\section{Introduction}

As a very important parameter of irradiated reactor fuel, the burn-up allows the estimation of the quantities and the ratios of the isotopes produced in a nuclear reactor. In radioecological practice after the accident at the Chernobyl nuclear power plant (NPP), the average burn-up value calculated for the reactor core was often used for an estimation of the amounts of different actinide isotopes in the nuclear fallout by applying corresponding correlation ratios for different isotopes. In particular, this approach was used for the retrospective estimations of irradiation doses created by short-lived radionuclides, if corresponding monitoring had been not performed at the proper time.

According to calculations by Begichev et al. [1], the average burn-up of the $4^{\text {th }}$ Chernobyl reactor was about 11.4 MWd/(kg U) when the reactor was destroyed. However, the real burn-up varied significantly over the reactor core, because spent fuel had been gradually replaced by

\footnotetext{
*Author for correspondence (E-mail: boulyga@uni-mainz.de).
}

freshly enriched uranium and the fuel assemblies had different core histories. Fig. 1 demonstrates the distribution of the burn-up of reactor uranium in the $4^{\text {th }}$ Chernobyl reactor [1]. During the accident, the fuel assemblies were for the most part destroyed and a partial homogenization of irradiated uranium occurred. This especially concerned the fine particulate fuel fraction which was distributed over large distances from the reactor. However, because of the heterogeneity of nuclear fuel burn-up in the reactor core and in view of the fact that only a relatively small amount of the irradiated nuclear fuel (according to the most plausible estimations it was about 3\%) entered the atmosphere, the real burn-up and the isotopic composition of actinides and fission products could vary in different contaminated areas. In addition, the accidental release of irradiated fuel continued for several days whereas the wind directions, and hence radionuclide spread, changed during different stages of the reactor accident.

Different approaches can be applied for evaluating the burn-up of Chernobyl reactor fuel by using, for instance, isotope ratios of fission products (caesium, neodymium etc.) or actinide (uranium, plutonium) isotope ratios [2]. The determination of uranium isotope ratios allows a direct evaluation of the degree of utilization of enriched reactor fuel, and as such represents the easiest way to calculate the burn-up. However, in contaminated soil samples, reac-

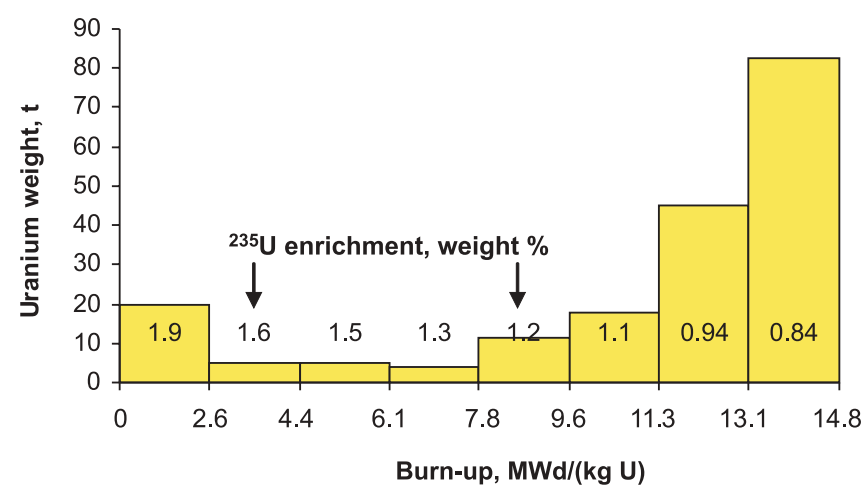

Fig. 1. Burn-up distribution and ${ }^{235} \mathrm{U}$ enrichment in fuel fractions of the damaged Chernobyl reactor, calculated data by Begichev et al. [1]. 
tor uranium is mixed with natural uranium and therefore the ${ }^{235} \mathrm{U} /{ }^{238} \mathrm{U}$ isotope ratio deviates significantly. On the other hand, ${ }^{236} \mathrm{U}\left(T_{1 / 2}=2.3416 \times 10^{7}\right.$ years $)$ was found with very low abundance in natural uranium $\left(\right.$ the ${ }^{236} \mathrm{U} /{ }^{238} \mathrm{U}$ ratios measured recently in natural uranium ores [3-6] ranged from $1.2 \times 10^{-11}$ to $5.6 \times 10^{-10}$ ), but it is produced in nuclear reactors via the ${ }^{235} \mathrm{U}(n, \gamma)^{236} \mathrm{U}$ reaction [7] (with a cross section of 95 barns for thermal neutrons vs. a fission cross section of 586 barns) and, to a lesser extent, by the alpha decay of ${ }^{240} \mathrm{Pu}$. Thus, the determination of uranium concentration (using the isotope dilution technique) and burnup of irradiated nuclear fuel in contaminated soil samples is also possible via the measured isotope ratios of uranium ${ }^{236} \mathrm{U} /{ }^{238} \mathrm{U}$ and $\left.{ }^{235} \mathrm{U} /{ }^{238} \mathrm{U}\right)$. Accelerator mass spectrometry (AMS) [3-5] and thermal ionization mass spectrometry (TIMS) [5] are well established techniques for uranium isotopic measurements but these methods are expensive and sample preparation is time consuming. Inductively coupled plasma mass spectrometry (ICP-MS) provides high sensitivity, good accuracy of isotopic measurements, and a relatively simple sample preparation procedure $[8,9]$ and, therefore, is one of the mostly suitable methods for routine uranium isotopic ratio determination in environmental samples.

The aim of this work was the determination of the average burn-up values of irradiated uranium in contaminated soils collected at 11 sampling sites within a 30-km unpopulated area around Chernobyl NPP and at one sampling site near Choiniki, situated $53 \mathrm{~km}$ to the north of the Chernobyl NPP by using uranium isotopic measurements. The data obtained will be used to define more exactly levels of contamination with irradiated uranium and other radionuclides in the investigated areas.

\section{Experimental}

\section{Samples}

Soil samples were taken $4-53 \mathrm{~km}$ to the north and west of Chernobyl NPP (Fig. 2) in areas undisturbed by technogenic and anthropogenic activities since the Chernobyl accident. Soil was sampled with a coring device that was specially designed to cut $10 \mathrm{~cm}$ thick soil layers down to $60 \mathrm{~cm}$. The collected soil samples were sieved through a $1.0 \mathrm{~mm}$ screen for the removal of stones and fragments of plant roots, and carefully mixed; then the samples were dried to constant weight at $105 \pm 5^{\circ} \mathrm{C}$. After homogenization, $250 \mathrm{~g}$ of the sample was incinerated at $600 \pm 50^{\circ} \mathrm{C}$ for 1 hour. Plant roots and vegetation were incinerated separately at $550 \pm 50^{\circ} \mathrm{C}$ in an oven with oxygen supply for 2 hours and then the ash was mixed with the sample. Then the sample was leached with $9 \mathrm{M} \mathrm{HCl}$. It was shown by Mironov et al. [10] that uranium originating from Chernobyl reactor is preferably extracted from soil samples into liquid $9 \mathrm{M} \mathrm{HCl}$ medium in comparison to the natural uranium in the hexavalent state. Therefore, this approach allowed partial isolation of reactor uranium for the following determination of its burn-up. After leaching by $\mathrm{HCl}$, uranium was extracted by ion-exchange chromatography using anionite resin AB-17 (Joint Stock Company Azot, Novomoskovsk, Russia) and extraction with diethyl ether [10].

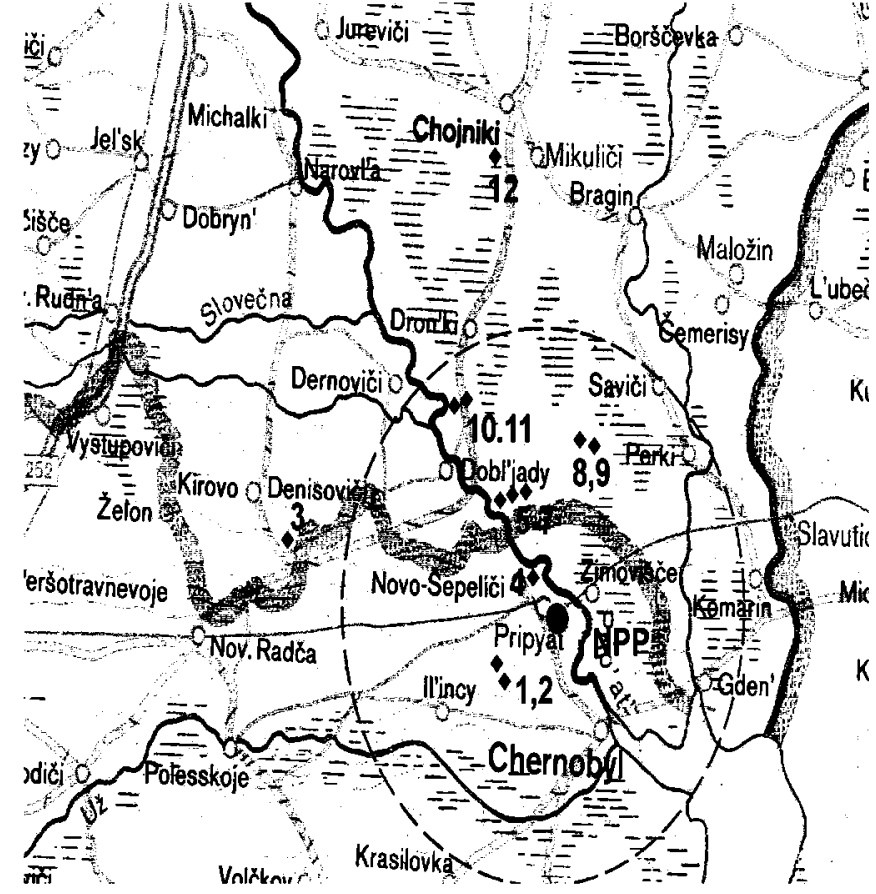

Fig. 2. Map of the sampling sites in the Chernobyl vicinity.

The concentration of uranium in the soil samples was measured by parallel analyses of the same samples using isotope dilution with ${ }^{233} \mathrm{U}\left({ }^{233} \mathrm{U}\right.$ abundance of $\left.99.9 \%\right)$ as isotope spike. $2 \mathrm{~g}$ of the incinerated soil sample was spiked with a known quantity of ${ }^{233} \mathrm{U}$ tracer isotope and digested in a microwave oven with a mixture of nitric acid and hydrofluoric acid. The solution was evaporated, the residue was boiled on a hot plate with concentrated $\mathrm{HClO}_{4}$, evaporated again, and then dissolved and separated by ion-exchange chromatography as described above.

\section{Instrumentation and measurement procedure}

A double-focusing sector-field inductively coupled plasma mass spectrometer (ICP-MS ELEMENT, Thermo Electron, Bremen, Germany) with a low-flow microconcentric nebulizer (MCN) with membrane desolvator (Aridus, CETAC Technologies Inc., Omaha, Nebraska, USA) $[8,9]$ was used for isotopic ratio measurements of uranium in aqueous solution after digestion of soil sample and chemical separation of uranium.

An isotopic standard solution of uranium (CCLU-500 laboratory standard, Nuclear Research Center, Prague, Czech Republic [11]) was used for optimizing isotope ratio measurements of uranium. Uranium solution with natural isotopic composition was prepared as described elsewhere [12]. All reagents were diluted with deionized Milli$\mathrm{Q}$ water $(18 \mathrm{M} \Omega)$ obtained from a Millipore Milli-Q-Plus water purifier to the necessary concentrations for determining the isotopic ratios of uranium by ICP-MS. The solutions were acidified to with $1 \%$ subboiled $\mathrm{HNO}_{3}$. Optimization of the experimental parameters of ICP-SFMS was performed with respect to the maximal ion intensity of ${ }^{238} \mathrm{U}^{+}$and minimal uranium hydride formation rate using a $1 \mu \mathrm{gl}^{-1}$ natural uranium solution introduced by the MCN with Aridus desolvator. The measured uranium isotopic ratio in soil samples 
was corrected taking into account the mass discrimination factor, assuming a linear correlation $[13,14]$ determined experimentally by measuring CCLU-500 standard solution as well as hydride rate $\mathrm{UH}^{+}$ratios and the dead time of the detector of the ICP-MS [15]. The combined uncertainty of isotopic ratio measurements was calculated according to the EURACHEM/CITAC Guide [16] taking into account standard deviations of the measured ratio, background (including instrument background and interfering hydride ions) uncertainties of mass discrimination factor and the dead time and uncertainty associated with uranium isotopic standard.

\section{Method for determination of burn-up and concentration of irradiated uranium}

The burn-up and concentration of irradiated uranium in soil samples was determined by using experimentally measured ${ }^{235} \mathrm{U} /{ }^{238} \mathrm{U}$ and ${ }^{236} \mathrm{U} /{ }^{238} \mathrm{U}$ isotope ratios and calculated correlation coefficients between uranium isotopes in the reactor core, which depend on the burn-up of irradiated uranium.

A detailed analysis of the dependence of the isotopic composition of nuclear fuel ${ }^{235} \mathrm{U},{ }^{236} \mathrm{U},{ }^{238} \mathrm{U},{ }^{239} \mathrm{Pu},{ }^{240} \mathrm{Pu}$ etc.) on burn-up in different reactors is performed in [17]. For RBMK (Chernobyl-type) reactors, some differences in concentrations and isotopic compositions of the radionuclides produced can take place even at the same burn-up depending on the location of fuel in the reactor core. These differences are mainly due to the changing of the coolant density with the height of the technological channels and variations of the neutron spectrum in different zones of the reactor core.

Taking account of the neutron-physical parameters of the Chernobyl reactor (design peculiarities of fuel assemblies, coolant density etc.) the neutron spectral density distribution was evaluated in the reactor core and the concentration ratios of ${ }^{236} \mathrm{U},{ }^{235} \mathrm{U}$ and ${ }^{238} \mathrm{U}$ isotopes were estimated as functions of burn-up with a relative uncertainty of less than $5 \%$ with respect to the whole range of possible coolant densities and local peculiarities of neutron spectra in different reactor core zones.

Based on these data, determination of burn-up $B$ was performed from the following approximated equation:

$$
154 B^{-1.346}-4180 \delta B^{-0.817}=(\beta-\delta) / \alpha,
$$

where $\delta=\rho_{5.0} / \rho_{8.0}$ is ${ }^{235} \mathrm{U} /{ }^{238} \mathrm{U}$ concentration ratio in natural uranium; $\alpha=\rho_{6, *} /\left(\rho_{8,0}+\rho_{8, *}\right)$ and $\beta=\left(\rho_{5,0}+\rho_{5, *}\right) /\left(\rho_{8,0}\right.$ $\left.+\rho_{8, *}\right)$ are measured ${ }^{236} \mathrm{U} /{ }^{238} \mathrm{U}$ and ${ }^{235} \mathrm{U} /{ }^{238} \mathrm{U}$ concentration ratios, respectively.

Spent reactor uranium concentration $\rho^{*}=\rho_{5, *}+\rho_{6, *}+$ $\rho_{8, *}$ was calculated using the following equations: $\rho_{5, *} / \rho_{6, *}=$ $154 B^{-1.346}$ and $\rho_{8, *} / \rho_{6, *}=4180 B^{-0.817}$. The above equations contain the following symbols: $\rho_{5,0}$ - concentration of ${ }^{235} \mathrm{U}$ originating from natural uranium in soil sample $\mathrm{g} / \mathrm{kg} ; \rho_{5, *}$ - concentration of ${ }^{235} \mathrm{U}$ originating from irradiated uranium in soil sample $\mathrm{g} / \mathrm{kg} ; \rho_{8,0}$ - concentration of ${ }^{238} \mathrm{U}$ originating from natural uranium in soil sample $\mathrm{g} / \mathrm{kg} ; \rho_{8, *}-$ concentration of ${ }^{238} \mathrm{U}$ originating from irradiated uranium in soil sample $\mathrm{g} / \mathrm{kg} ; \rho_{6, *}-$ concentration of ${ }^{236} \mathrm{U}$ originating from irradiated uranium in soil sample $\mathrm{g} / \mathrm{kg} ; B$ - burn-up, $\mathrm{g} /(\mathrm{kg} \mathrm{U})$.

\section{Results}

${ }^{236} \mathrm{U}$ was detected in all soil samples collected to the north and west of Chernobyl NPP (resettlement area and some populated regions) at distances of $4 \mathrm{~km}$ to $53 \mathrm{~km}$ pointing to contamination with spent nuclear fuel. The occurrence of ${ }^{236} \mathrm{U}$ in soil samples is evidence for contamination due to nuclear fallout from the Chernobyl accident. As uranium with natural isotopic composition is mixed with spent reactor uranium in contaminated soil samples, the observed uranium isotope ratios deviate in a relatively wide range, i.e. the ${ }^{235} \mathrm{U} /{ }^{238} \mathrm{U}$ and ${ }^{236} \mathrm{U} /{ }^{238} \mathrm{U}$ isotope ratios range from $7.25 \times 10^{-3}$ to $1.04 \times 10^{-2}$ and from $7 \times 10^{-7}$ to $1.2 \times 10^{-3}$, respectively (Table 1). The determination of ${ }^{235} \mathrm{U} /{ }^{238} \mathrm{U}$ and ${ }^{236} \mathrm{U} /{ }^{238} \mathrm{U}$ isotopic ratios by ICP-SFMS revealed the portion of nuclear fuel in the spent uranium/natural uranium mixture and provided information about the degree of burn-up of spent reactor uranium. Table 2 presents the results of cal-

Table 1. Variation of uranium isotope ratios in contaminated Chernobyl soil samples.

\begin{tabular}{llc}
\hline Isotope ratio & Chernobyl soil samples & In nature [6] \\
\hline${ }^{234} \mathrm{U} /{ }^{238} \mathrm{U}$ & $0.000055-0.000117$ & 0.000055 \\
${ }^{235} \mathrm{U} /{ }^{238} \mathrm{U}$ & $0.00725-0.0104$ & 0.00725 \\
${ }^{236} \mathrm{U} /{ }^{238} \mathrm{U}$ & $0.0000007-0.0012$ & $<10^{-9}$ \\
\hline
\end{tabular}

Table 2. Soil types at sampling sites, measured concentrations of irradiated uranium and its burn-up in upper $0-10 \mathrm{~cm}$ soil layer (sampling points $1-3$ are situated on the western Chernobyl fallout tail, sampling points $4-12$ are situated on the northern Chernobyl fallout tail).

\begin{tabular}{lllccc}
\hline $\begin{array}{l}\text { Sampling } \\
\text { point }\end{array}$ & Name & Soil type & $\begin{array}{c}\text { Distance, } \\
\mathrm{km}\end{array}$ & $\begin{array}{c}\text { Concentration of } \\
\text { irradiated uranium } \\
\text { in soil, } \mu \mathrm{g} \mathrm{g}^{-1}\end{array}$ & $\begin{array}{c}\text { Burn-up, } \\
\text { MWd/(kg U) }\end{array}$ \\
\hline 1 & Chistogalovka & turf-podzol, sand-clay & 7 & 0.76 & 9.3 \\
2 & Chistogalovka & Peat & 7 & 2.0 & 9.1 \\
3 & Hatki & turf-podzol, sand & 24 & $2.1 \times 10^{-3}$ & 9.2 \\
4 & Pripyat & Sand & 4 & 0.81 & 9.3 \\
5 & Masany & turf-podzol, sand-clay & 12 & 0.78 & 9.9 \\
6 & Masany & turf-podzol, sand-clay & 12.5 & $2.5 \times 10^{-2}$ & 9.3 \\
7 & Masany & Peat & 12.5 & 1.2 & 9.6 \\
8 & Kulazhin & turf-podzol, sand & 18 & $6.3 \times 10^{-3}$ & 9.2 \\
9 & Kulazhin & Peat & 18 & $4.3 \times 10^{-3}$ & 9.3 \\
10 & Lesok & turf-podzol, sand & 24 & $2.7 \times 10^{-2}$ & 9.4 \\
11 & Lesok & Peat & 24 & $1.2 \times 10^{-1}$ & 9.4 \\
12 & Chojniki & turf-podzol, sand-clay & 53 & $1.3 \times 10^{-2}$ & 7.7 \\
\hline
\end{tabular}


culating the concentration of irradiated reactor uranium in soil samples and its burn up at 12 sampling sites. Sampling sites 1-3 were selected on the western fallout tail and points 4-12 were selected on the northern fallout tail injected from the damaged Chernobyl reactor. The concentration of Chernobyl spent uranium in the upper $0 \mathrm{~cm}-10 \mathrm{~cm}$ soil layers in areas investigated in the vicinity of Chernobyl NPP amounts to $2.1 \times 10^{-9} \mathrm{~g} / \mathrm{g}$ to $2.0 \times 10^{-6} \mathrm{~g} / \mathrm{g}$, depending mainly on the distance from the Chernobyl reactor. In general, the portion of spent uranium decreases with increasing distance from the Chernobyl NPP and the highest concentrations of spent uranium were observed in soils within radioactive spots closest to the Chernobyl NPP (Chistogalovka, Pripyat, Masany).

The calculated burn-up of reactor uranium in all soil samples within the 30-km area around the Chernobyl NPP was similar and the average value amounted to about $9.4 \pm$ $0.3 \mathrm{MWd} /(\mathrm{kg} \mathrm{U})$. This value is about $17 \%$ lower than the average burn-up over the reactor core calculated by Begichev et al. [1] In the Choiniki area, a lower burn-up of $7.7 \mathrm{MWd} /(\mathrm{kg} \mathrm{U})$ was observed. It should be mentioned that the concentration of irradiated Chernobyl uranium in Choiniki was relatively low, and therefore, the uncertainty of the burn-up determination was greater.

\section{Conclusion}

${ }^{235} \mathrm{U} /{ }^{238} \mathrm{U}$ and ${ }^{236} \mathrm{U} /{ }^{238} \mathrm{U}$ isotope analysis in soil samples after digestion and analyte separation by ICP-SFMS allowed the determination of the concentration of irradiated reactor uranium in the reactor/natural uranium mixture and the estimation of reactor uranium burn-up. The measurement of uranium isotope ratios provides direct information on the burn-up of spent uranium in contrast to calculation methods based on isotope ratios of fission products $\left(\right.$ e.g. ${ }^{134} \mathrm{Cs} /{ }^{137} \mathrm{Cs}$ isotope ratio).

A slight variation of the burn-up grade of irradiated uranium was observed in this work. In particular, the burn up of reactor uranium in soil samples collected outside the $30-\mathrm{km}$ area around the Chernobyl NPP differed from the burn-up value in soils samples collected close to the destroyed reactor. Within the $30-\mathrm{km}$ area, the burn-up was similar on both western and northern fallout tails. Therefore, the same correlation coefficients for transuranium radionuclides originating from the destroyed Chernobyl reactor can be used for all investigated regions within the $30-\mathrm{km}$ area, but outside this area the correlation coefficients might differ.

\section{References}

1. Begichev, S. N., Borovoj, A. A., Burlakov, E. B., Gagarinsky, A. J., Demin, V. F., Khrulev, A. A., Khodakovsky, I. L.: Radioactive release due to the Chernobyl accident. In: Fission Product Transport Processes in Reactor Accidents. (Rogers, J. T., ed.) Hemisphere, New York (1990) p. 717.

2. Pasukhin, E. M., Makarova, T. P., Stepanov, A. V., Belyaev, B. N.: Burn-up of nuclear fuel in destroyed reactor of the fourth block of the Chernobyl nuclear power plant. Radiochemistry 42, 527 (2000)

3. Zhao, X.-L., Kilius, L. R., Litherland, A. E., Beasley, T.: AMS measurement of environmental U-236. Preliminary results and perspectives. Nucl. Instrum. Methods B 126, 297 (1997).

4. Zhao, X.-L., Nadeau, M.- J., Kilius, L. R., Litherland, A. E.: The first detection of naturally-occurring ${ }^{236} \mathrm{U}$ with accelerator mass spectrometry. Nucl. Instrum. Methods B 92, 249 (1994).

5. Berkovits, D., Feldstein, H., Ghelberg, S., Hershkowitz, A., Navon, E., Paul, M.: ${ }^{236} \mathrm{U}$ in uranium minerals and standards. Nucl. Instrum. Methods B 172, 372 (2000).

6. Richter, S., Alonso, A., De Bolle, W., Wellum, R., Taylor, P. D. P.: Isotopic "fingerprints" for natural uranium ore samples. Int. J. Mass Spectrom. 193, 9 (1999).

7. Ghiorso, A., Brittain, J. W., Manning, W. M., Seaborg, G. T., The uranium isotope ${ }^{236}$ U. Phys. Rev. 82, 558 (1951).

8. Boulyga, S. F., Matusevich, J. L., Mironov, V. P., Kudrjashov, V. P., Halicz, L., Segal, I., McLean, J. A., Montaser, A., Becker, J. S.: Determination of ${ }^{236} \mathrm{U} /{ }^{238} \mathrm{U}$ ratio in contaminated environmental samples using different ICP-MS instruments. J. Anal. Atom. Spectrom. 17, 958 (2002).

9. Boulyga, S. F., Becker, J. S.: Isotopic analysis of uranium and plutonium using ICP-MS and estimation of burn-up of spent uranium in contaminated environmental samples. J. Anal. Atom. Spectrom. 17, 1143 (2002)

10. Mironov, V. P., Matusevich, J. L., Kudrjashov, V. P.: Method of uranium determination in soil and aerosol filters. Standard Method RB N MVI MH 1497, Minsk (2001).

11. Dietze, H.-J.: Berichte des Zentralinstituts fuer Isotopen und Strahlenforschung der Akademie der Wissenschaften der DDR 27, 101 (1979).

12. Boulyga, S. F., Becker, J. S., Matusevitch, J. L., Dietze, H. J.: Isotope ratio measurements of spent reactor uranium in environmental samples by using inductively coupled plasma mass spectrometry. Int. J. Mass Spectrom. 203, 143 (2000).

13. Taylor, P. D. P., De Bievre, P., Walder, A. J., Entwistle, A.: Validation of the analytical linearity and mass discrimination correction model exhibited by a multiple collector inductively coupled plasma mass spectrometer by means of a set of synthetic uranium isotope mixtures. J. Anal. Atom. Spectrom. 10, 395 (1995).

14. Heumann, K. G., Gallus, S. M., Raedlinger, G., Vogl, J.: Precision and accuracy in isotope ratio measurements by plasma source mass spectrometry. J. Anal. At. Spectrom. 13, 1001 (1998).

15. Kerl, W., Becker, J. S., Dietze, H. J.: Isotopic and ultratrace analysis of uranium by double-focusing sector field ICP mass spectrometry. Fresenius J. Anal. Chem. 359, 407 (1997).

16. Ellison, S. L. R., Rosslein, M., Williams, A. (eds.): EURACHEM/ CITAC Guide. Quantifying Uncertainty in Analytical Measurement, Second Edition, London (2000).

17. Gerasimov, A. S.: Reference book on nuclide production in nuclear reactors. Energoatomizdat, Moscow (1989). 